\title{
GCU
}

Glasgow Caledonian

University

University for the Common Good

\section{Rock-concrete interfacial crack propagation under mixed mode I-II fracture}

Dong, Wei; Yang, Dong; Zhang, Ben; Wu, Zhimin

Published in:

Journal of Engineering Mechanics

DOI:

10.1061/(ASCE)EM.1943-7889.0001461

Publication date:

2018

Document Version

Author accepted manuscript

Link to publication in ResearchOnline

Citation for published version (Harvard):

Dong, W, Yang, D, Zhang, B \& Wu, Z 2018, 'Rock-concrete interfacial crack propagation under mixed mode I-II fracture', Journal of Engineering Mechanics, vol. 144, no. 6. https://doi.org/10.1061/(ASCE)EM.1943-

7889.0001461

\section{General rights}

Copyright and moral rights for the publications made accessible in the public portal are retained by the authors and/or other copyright owners and it is a condition of accessing publications that users recognise and abide by the legal requirements associated with these rights.

Take down policy

If you believe that this document breaches copyright please view our takedown policy at https://edshare.gcu.ac.uk/id/eprint/5179 for details of how to contact us. 
$5{ }^{1}$ Associate Professor, State Key Laboratory of Coastal and Offshore Engineering, Dalian University 6 of Technology \& Ocean Engineering Joint Research Centre of DUT-UWA, Dalian 116024, P. R.

7 China. E-mail: dongwei@dlut.edu.cn

8 *Corresponding author

$9 \quad{ }^{2}$ Postgraduate student, State Key Laboratory of Coastal and Offshore Engineering, Dalian University 10 of Technology, Dalian 116024, P. R. China. E-mail: dongyang@mail.dlut.edu.cn

$11{ }^{3}$ Professor, Department of Construction and Surveying, School of Engineering and Built 12 Environment, Glasgow Caledonian University, Glasgow G4 0BA, Scotland, United Kingdom. E-mail:

$13 \quad$ Ben.Zhang@gcu.ac.uk

$14{ }^{4}$ Professor, State Key Laboratory of Coastal and Offshore Engineering, Dalian University of 15 Technology, Dalian 116024, P. R. China. E-mail: wuzhimin@dlut.edu.cn 
Abstract

Experimental tests were conducted on the composite rock-concrete specimens with four roughness profiles to investigate the propagation process of interfacial cracks under three-point bending and four-point shear conditions. By measuring the initial fracture loads, various combinations of interfacial stress intensity factors (SIFs) of modes I and II corresponding to the initial fracture conditions were determined. Based on these results, an expression for classifying the initiation of interfacial cracks under the mixed mode I-II fracture was derived by normalization, which could eliminate the effect of interfacial roughness. Furthermore, a criterion for specifying the propagation of the interfacial crack by considering the nonlinear interfacial characteristics was proposed, which indicates that the crack would start to propagate along the interface when the SIFs caused by the external loads and the cohesive stresses satisfied this criterion. The numerical simulations on the 
49 The operational safety of concrete gravity hydraulic dams is often threatened by the interfacial cracks between the concrete dams and the rock foundations, which are generally caused by the initial defects during construction or complex loading and environmental effects during service. The propagation of these interfacial cracks under hydrostatic pressure will decrease the load-carrying capacity and result in fracture and failure of the structures. In particular, various propagation paths of the interfacial cracks determine failure patterns of concrete dams on rock foundations. Therefore, it is significantly important to predict the fracture process and potential crack trajectory to ensure safety, serviceability and durability of a mass concrete hydraulic dam under service loading conditions.

For a rock-concrete interfacial crack, there are generally three potential propagation paths: (i) propagating fully along the interface until the structure fails; (ii) propagating first along the interface and then kinking into one material; and (iii) kinking into one material after it initiates. It has been verified by experiment that the interfacial crack may follow Path 1 at a low mode mixity ratio $K_{2} / K_{1}$ (Zhong et al. 2014) and is prone to Paths 2 and 3 at a high $K_{2} / K_{1}$ ratio (Slowik et al. 1998). Here, $K_{1}$ and $K_{2}$ are the stress intensity factors (SIFs) for fracture modes I and II at the tip of an interfacial crack, respectively. However, the crack propagation path is governed not only by the magnitude in the stress field of the crack tip, but also by the material and interface properties. Therefore, for the purpose of the fracture analysis, a criterion for interfacial crack propagation, which can evaluate the balance between the effects of the external loads and the resistance of the materials or interface, should be developed.

So far, a number of criteria have been proposed for the fracture at rock-concrete interface, classified as stress-based (Červenka et al. 1998), energy-based (Qian and Sun 1998, Sujatha and 
Kishen 2003) and SIF-based criteria (Kishen and Singh 2001, Zhong et al. 2014, Dong et al. 2016a).

71 For a small fracture process zone (FPZ) at the crack tip, linear elastic fracture mechanics (LEFM) was often employed to establish the criterion and analyze the fracture behavior at the rock-concrete interface (Červenka et al. 1998, Qian and Sun 1998, Sujatha and Kishen 2003, Kishen and Singh 2001, Yang et al. 2008). From a practical point of view, the simplification by disregarding the FPZ is acceptable for a mega structure, e.g. a gravity concrete hydraulic dam on the rock foundation. nonlinear fracture theory will be more appropriate for assessing the effect of the FPZ on fracture behavior. Particularly, due to the cohesive action on the FPZ, the stress field at the tip of an interfacial crack will change, resulting in transformation of the crack path. In addition, in the case of low mode mixity ratio, the propagation of an interfacial crack was treated as pure mode I fracture. Consequently, the mode I dominated criterion was used to determine crack propagation by assuming the crack path along the interface (Zhong et al. 2014, Dong et al. 2016a). In fact, the propagation of an interfacial crack under mixed mode I-II stress conditions can be predicted by using the formulas including fracture parameters for modes I and II (Slowik et al. 1998). The interface resistance will be over-estimated if only mode I parameter is utilized. Finally, it should be mentioned that some interface fracture criteria were derived only for homogeneous materials, i.e. the maximum circumferential stress (Ryoji and Xu 1992), the net SIF (Moës and Belytschko 2002), and the initial fracture toughness (Dong et al. 2013, Wu et al. 2013). There is a remarkable knowledge gap in the criteria for fracture and failure in homogenous materials and at bi-material interfaces. Hence, a criterion based on the fracture experiment at rock-concrete interface may be more appropriate for 91 fracture analysis of mass concrete structures on rock foundations. 
For cementation materials like concrete, the complete fracture process includes three stages:

crack initiation, stable propagation and unstable propagation (Xu and Reinhardt 1999a, 1999b).

These stages are also applicable for the interface fracture (Dong et al. 2016b). Regarding the cohesive effect on the FPZ under external loading, each step of the propagation of the fictitious crack can be taken as the initiation of a new crack, so that a complete fracture process consists of formations of many new cracks. A criterion used for determining the initiation of a crack can be utilized in the analysis on the crack propagation by introducing the cohesive force acting on the FPZ. This idea has been verified by the numerical simulations of the mode I fracture and mixed I-II fracture of concrete (Dong et al. 2013, Wu et al. 2013). It should be noted that the initiation and propagation of the crack in concrete is still governed by the tensile resistance although the crack tip is under a mixed mode I-II stress state. In these studies, only the initial fracture toughness of mode I was introduced as a material property. However, the scenario is different in the case of the rock-concrete interface under the mixed mode I-II fracture, because the interface is much weaker than the materials on both sides of the crack. Under this condition, the crack is prone to propagating along the interface, rather than being mode I dominated. Therefore, it is a challenge to explore what stress conditions can cause an interfacial crack to propagate, and to predict whether the crack can branch from the interface and kink into a material on one side of the interface.

The objective of this study, therefore, is to develop a criterion for predicting the propagation of the rock-concrete interfacial crack based on the initial fracture toughness and determining potential paths for the propagation of the crack. First, composite rock-concrete specimens with four interfacial roughness profiles are to be tested under three-point bending (TPB) and four-point shear (FPS). By adjusting the loading position in FPS, a wide range of $K_{2} / K_{1}$ ratios corresponding to the initial 
114 cracking load can be obtained. A criterion for specifying the propagation of an interfacial crack based on the initial fracture toughness will then be derived by analyzing the experimental data. Thereafter,

116 the criterion is to be employed in the numerical simulation on the interface fracture and verified by 117 comparing the numerical results with the experimental data. Finally, combining the criterion with the 118 material properties on both sides of the interface, potential crack propagation paths can be 119 determined. It is expected that this investigation is to provide a better understanding of the fracture 120 mechanism for the rock-concrete interface so that the load-carrying capacity and the serviceability and durability of mass concrete structures on rock foundations can be evaluated more accurately.

\section{Experimental Program}

\section{Specimen preparation}

Two types of specimens were prepared for the experimental study: composite rock-concrete beams and prisms with artificially grooved surfaces for the rock sections. The dimensions of the composite beams for the TPB and FPS tests were $500 \mathrm{~mm} \times 100 \mathrm{~mm} \times 100 \mathrm{~mm}$, while the dimensions of the prism specimens for the direct tension tests were $200 \mathrm{~mm} \times 100 \mathrm{~mm} \times 100 \mathrm{~mm}$. In addition, in order to obtain the fracture parameters of the rock and concrete, individual rock and concrete beams of $500 \mathrm{~mm} \times 100 \mathrm{~mm} \times 100 \mathrm{~mm}$ were also prepared for the TPB tests. The geometries of the composite specimens under the TPB and FPS tests are illustrated in Figs. 1(a) and (b). Each composite beam was made up of two portions, i.e. the concrete and rock sections. In the TPB tests, the lengths of the concrete and rock sections were identical, $250 \mathrm{~mm}$ each. In the FPS tests, the lengths of the rock sections varied from $225 \mathrm{~mm}$ to $250 \mathrm{~mm}$ to cover a wide range of mode mixity ratios for the concrete-rock (C-R) series beams. For each composite beam, the length of the 
pre-crack, $a_{0}$, was $30 \mathrm{~mm}$. In order to achieve the pre-crack, two layers of PVC film were put at the location of the pre-crack on the rock, where one PVC film was pasted on the surface of the rock using glue and another one was fixed at the same position using cello tape (see Fig. 2). Then the concrete was cast against the rock section in the mold and the PVC film fixed with cello tape could bond well with the concrete. Before testing, the cello tape was pulled out to eliminate the bonding effect between the two layers of the PVC film.

To obtain the surfaces with various roughness degrees between the rock and concrete, four levels of interfacial roughness were adopted by introducing artificial groove lines on the contact surfaces of the rock sections in this study. The groove lines were parallel to the diagonal lines of the and $7 \times 7$, respectively, as illustrated in Figs. 3(a) to (d). The degree of roughness, $R_{\mathrm{a}}$, is quantified by cured for 28 days in the curing chamber with a $23^{\circ} \mathrm{C}$ curing temperature and $90 \%$ relative humidity. of $R_{\mathrm{a}}$ is the average for the composite specimens with the same artificial groove pattern. Fig. 3(e) illustrates the values of the $R_{\mathrm{a}} / M_{\text {size }}$ ratio for different roughness profiles where $M_{\text {size }}$ is the maximum size of crushed aggregate which was $10 \mathrm{~mm}$ for the concrete used in this study.

The rock used for the composite beams was granite, prepared in Dalian, Liaoning Province of China. The composite beams and prisms were fabricated by casting concrete against the rough surfaces of the rock sections. The concrete mix design was cement : water : sand : aggregate $=$ 1:0.60:2.01:3.74 by weight. The composite specimens were demolded one day after casting, and then Three specimens were prepared for each loading condition and roughness profile. 
The mechanical properties of the concrete and rock materials and the rock-concrete interfaces

are listed in Table1, where $E$ is the elastic modulus, $\rho$ is the density, $v$ is the Poisson's ratio, $f_{\mathrm{t}}$ is the uniaxial tensile strength, $f_{\mathrm{c}}$ is the uniaxial compressive strength, $K_{\mathrm{I}}^{\mathrm{ini}}$ is the initial fracture toughness of mode I, and $G_{\text {If }}$ is the fracture energy, respectively. It should be noted that the uniaxial tensile strength of the rock-concrete interface was obtained on the prism specimens tested in direct tension.

\section{TPB and FPS tests}

The composite TPB and FPS specimens with four interfacial roughness profiles were tested in a $250 \mathrm{kN}$ closed-loop servo MTS testing machine at a displacement rate of $0.024 \mathrm{~mm} / \mathrm{min}$. The experimental setups for the TPB and FPS tests are illustrated in Figs. 4(a) and (b), respectively. The ratio of loads on the two loading points is 1:6 for all C-R series specimens under FPS. The displacement at the loading point, the crack mouth opening displacement $(C M O D)$ and the crack mouth sliding displacement (CMSD) were measured using clip gauges in the test. In addition, to measure the initial cracking load, two strain gauges were symmetrically put on both sides of the specimen, $5 \mathrm{~mm}$ away from the tip of the pre-notch in the ligament. Once the pre-crack began to propagate, the measured strains would drop rapidly due to the sudden release of the stored strain energy at the pre-crack in the specimen. By taking Specimen C-R-240-4×4-1 as an example, Fig. 5 illustrates the relationship between the load and strain at the tip of the pre-crack. It can be seen that the strain reached its maximum at the initial cracking loading $P_{\text {ini }}=23.32 \mathrm{kN}$, and thereafter the strain started to decrease. The decrease in the strain indicates the release of the stored strain energy at the pre-crack tip so that the initial cracking load could be determined.

The experimental results for the TPB and FPS specimens are listed in Tables 2 and 3, respectively. The specimen number "TPB- $3 \times 3$ " in Table 2 denotes the TPB specimen with the $3 \times 3$ 
artificial groove pattern, see Fig. 1(a). $G_{\text {If }}$ in Table 2 denotes the fracture energy of mode I fracture for the interfaces with different roughness profiles. The specimen number "C-R-225-3×3" in Table 3 denotes the FPS specimen with the left and right sections as the concrete and rock, respectively. The length for the rock section was $225 \mathrm{~mm}$ with the $3 \times 3$ artificial groove pattern, see Fig. 1(b). Here, $P_{\text {ini }}$ and $P_{\max }$ are the initial and peak loads, and $L_{R}$ is the length of the rock section. The stress intensity factors $K_{1}$ and $K_{2}$ for the bi-material interfacial crack were calculated using Eqs. (1) to (7) below (Nagashima et al. 2003). Here, $\delta_{\mathrm{x}}$ and $\delta_{\mathrm{y}}$ are the relative crack surface diplacements in the horizontal $\mathrm{x}$ and vertical y directions. $K_{1}$ and $K_{2}$ can be writen as $K_{1}^{\mathrm{ini}}$ and $K_{2}^{\mathrm{ini}}$ when $\delta_{\mathrm{x}}$ and $\delta_{\mathrm{y}}$ in Eqs. (1) and (2) are caused by the initial cracking load:

$$
\begin{aligned}
& K_{1}=C \lim _{\mathrm{r} \rightarrow 0} \sqrt{\frac{2 \pi}{r}}\left[\delta_{\mathrm{y}}(\cos Q+2 \varepsilon \sin Q)+\delta_{\mathrm{x}}(\sin Q-2 \varepsilon \cos Q)\right] \\
& K_{2}=C \lim _{r \rightarrow 0} \sqrt{\frac{2 \pi}{r}}\left[\delta_{y}(\cos Q+2 \varepsilon \sin Q)-\delta_{x}(\sin Q-2 \varepsilon \cos Q)\right]
\end{aligned}
$$

191 where

192 the constant

$$
C=\frac{2 \cosh (\varepsilon \pi)}{\left(\kappa_{1}+1\right) / \mu_{1}+\left(\kappa_{2}+1\right) / \mu_{2}}
$$

193 the parameter

$$
Q=\varepsilon \ln r
$$

194 the stiffness parameter $\quad \varepsilon=\frac{1}{2 \pi} \ln \left(\frac{\frac{\kappa_{1}}{\mu_{1}}+\frac{1}{\mu_{2}}}{\frac{\kappa_{2}}{\mu_{2}}+\frac{1}{\mu_{1}}}\right)$

the shear modulii

$$
\mu_{\mathrm{i}}=\frac{E_{\mathrm{i}}}{2\left(+v_{\mathrm{i}}\right.} \quad(i=1,2)
$$

196 the elastic constants

$$
\kappa_{\mathrm{i}}=\left\{\begin{array}{l}
\left(3-v_{\mathrm{i}}\right) /\left(1+v_{\mathrm{i}}\right) \\
\left(3-4 v_{\mathrm{i}}\right)
\end{array}\right.
$$

(Plane stress)

(Plane strain)

$197 E_{\mathrm{i}}$ is the elastic modulus for material $i, v_{\mathrm{i}}$ is the Poisson's ratio for material $i, r$ is the radius of the 
pre-crack at its tip.

There are two basic failure modes for the composite C-R series beams under FPS. The interface

failure mode "I" means that the interfacial crack propagates through the interface until failure occurs. Some C-R series beams which fractured in this failure mode are shown in Fig. 6(a). The other failure mode "IC" was observed on the beams with high mode mixity ratios. Fig. 6(b) shows some examples of this failure mode. In the case of the failure mode "IC", a sudden brittle failure was observed near meso-structure, can be directly simulated. In this study, the concrete was modeled as the 
mesoscopic ones. The interfacial fracture energy and fracture toughness reflect the fracture charateristics at the interface on average. The effect of the interfacial roughness profile is considered through measuring the fracture energy and fracture toughness of the specimens with the same degree of roughness. These fracture parameters to be used in the following numerical simulations also corresponded to those from the specimens with the same degree of roughness.

\section{Criterion for Crack Propagation and Experimental Verification}

\section{Criterion for crack propagation}

From the experimental results, it can be found that the interfacial cracks can initiate under different combinations of $K_{1}^{\mathrm{ini}}$ and $K_{2}^{\mathrm{ini}}$. When the interfacial fracture was pure mode I, the crack initiation would be determined by the intial mode I fracture toughness, $K_{1 \mathrm{C}}^{\mathrm{ini}}$, i.e. $K_{1}^{\mathrm{ini}}=K_{1 \mathrm{C}}^{\mathrm{ini}}$ and $K_{2}^{\mathrm{ini}}=0$. When the fracture mode of interface was pure mode II, the crack initiation would be determined by the intial mode II fracture toughness, $K_{2}^{\text {ini }}$, i.e. $K_{1}^{\text {ini }}=0$ and $K_{2}^{\text {ini }}=K_{2 \mathrm{C}}^{\text {ini }}$. In addition, represent the crack initiation conditions under various combinations of tensile and shear stresses. Thus, the equation for the curve with the parameters $K_{1}^{\mathrm{ini}}$ and $K_{2}^{\mathrm{ini}}$ would become the criterion for the initiation of a crack. Through careful experimental design, a wide range of $K_{2}^{\text {ini }} / K_{1}^{\text {ini }}$ ratios could be derived from the TPB and FPS tests, varying from 0.055 to 16.595 , as illustrated Tables 2 and 3. Furthermore, the effect of the interface roughness on the crtierion for the crack initiation was investigated by testing the composite specimens with four roughness profiles. Fig. 8 illustrates the 
242 relationships between $K_{1}^{\mathrm{ini}}$ and $K_{2}^{\mathrm{ini}}$ from the testing data with various interface roughness degrees 243 and the fitted curves. It can be seen that the $K_{1}^{\text {ini }}$ versus $K_{2}^{\text {ini }}$ curve would move outward when $R_{\mathrm{a}}$ 244 increased from 0.780 to 1.548 , indicating that the interfacial cracking resistance would indeed 245 increase with the increasing interfacial roughness.

To derive the equation for the initial fracture by eliminating the effect of roughness degree, the normalizing method was utilized by dividing $K_{1}^{\mathrm{ini}}$ and $K_{2}^{\mathrm{ini}}$ by the corresponding $K_{1 \mathrm{C}}^{\mathrm{ini}}$ for each test series with the same $R_{\mathrm{a}}$. The points for the normalized terms $K_{1}^{\mathrm{ini}} / K_{1 \mathrm{C}}^{\mathrm{ini}}$ and $K_{2}^{\mathrm{ini}} / K_{1 \mathrm{C}}^{\mathrm{ini}}$ with various values of $R_{\mathrm{a}}$ are shown in Fig. 9. It can be seen that the effect of the interface roughness could be eliminated approximately through the normalizing process. Therefore, the regressive equation for the initial fracture could be derived by fitting all the scattered testing points as Eq. (8), where the shape of the equation for the initiation of the interfacial crack would be a quarter-ellipse, with the ratio of the long axial length to the short axial length as 1.6, i.e.

If a complete fracture process could be regarded as crack propagation for many steps, each step for the propagation of the existing crack would be regarded as the initiation of a new crack. Then, the 1976). Therefore, when the equation for the crack initiation was used to predict the propagation process of the crack, the SIFs, $K_{1}$ and $K_{2}$, would be governed by the external load and the cohesive force of the PFZ, i.e. $K_{1}=K_{1}^{\mathrm{P}}-K_{1}^{\sigma, \tau}$ and $K_{2}=K_{2}^{\mathrm{P}}-K_{2}^{\sigma, \tau}$. Here, $K_{1}^{\mathrm{P}}$ and $K_{2}^{\mathrm{P}}$ are the SIFs of modes I and II caused by the external load, while $K_{1}^{\sigma, \tau}$ and $K_{2}^{\sigma, \tau}$ are the SIFs of modes I and II 
caused by the cohesive tensile and shear stresses on the FPZ, $\sigma$ and $\tau$. Thus, Eq. (8) can be rewritten as Eq. (9) when it is used to determine the propagation of the crack along the interface, with $K_{1,2}^{*}$ representing the function of the criterion for the proapgation of the interficial crack:

$$
K_{1,2}^{*}=\sqrt{\left(\frac{K_{1}^{\mathrm{P}}-K_{1}^{\sigma, \tau}}{1}\right)^{2}+\left(\frac{K_{2}^{\mathrm{P}}-K_{2}^{\sigma, \tau}}{1.6}\right)^{2}}=K_{1 \mathrm{C}}^{\mathrm{ini}}
$$

In the case of mode I interface fracture, $K_{2}$ and the cohesive shear stress are equal to 0 so that

Eq. (9) will be degenerated to:

$$
K_{1}^{\mathrm{P}}-K_{1}^{\sigma}=K_{1 \mathrm{C}}^{\mathrm{ini}}
$$

Eq. (10) is the criterion of the crack propagation for the mode I interface fracture, which is a particular case of the mixed mode I-II fracture and has been verified in the previous research (Dong et al. 2016a).

\section{Application and experimental verification}

In order to verify the derived criterion for the propagation of the interfacial crack, numerical simulations based on the fictitious cracking model were conducted to predict the fracture process of the composite rock-concrete beams under TPB and FPS. The finite element analyses were carried out using commercial software ANSYS. The cohesive traction-displacement relationships for tension and shear softening are illustrated in Figs. 10(a) and (b), respectively. In Fig. 10(a), the crack opening displacement (COD) at the breaking point on the bi-linear $\sigma-w$ curve, $w_{\mathrm{n} 0}$, and the corresponding cohesive stress, $\sigma_{\mathrm{n} 0}$, were set as $0.8 G_{\mathrm{If}} / f_{\mathrm{t}}$ and $0.2 f_{\mathrm{t}}$, respectively. The stress-free COD, $w_{\mathrm{nc}}$, was set as $6 G_{\mathrm{If}} / f_{\mathrm{t}}$ (Dong et al. 2016c). In Fig. 10(b), the crack slip displacement (CSD) at the breaking point on the bi-linear $\tau$-w curve, $w_{\mathrm{s} 0}$, and the corresponding interface shear strength, $\tau_{\mathrm{s} 0}$, were set as $0.002 \mathrm{~mm}$ and $7 f_{\mathrm{t}} / 4$, respectively. The stress-free $\mathrm{CSD}, w_{\mathrm{sc}}$, was set as $2 G_{\text {IIf }} / \tau_{\mathrm{s} 0}$. Here, $G_{\text {IIf }}$ is the mode II interface fracture energy, which was set to be equal to $2 G_{\text {If }}$ (Zhong et al. 2014). 
If a pre-crack is assumed to initiate and propagate fully along the interface, the criterion for the

crack propagation can be used to predict the complete fracture process under the mixed mode I-II summarized as follows:

1. Establish the finite element model with the crack length $a_{\mathrm{i}, \mathrm{j}}=a_{0}+(j-1) \cdot \Delta a(i=1,2 \ldots ; j=2$, 3...). Here $a_{0}$ is the initial crack length, $\Delta a$ is a specified increment of the crack length, $i$ represents the load increment during the iteration process with a fixed crack length, and $j$ represents the increment of the crack length during the iterations.

2. Apply the load $P_{\mathrm{i}, \mathrm{j}}$ and calculate the cohesive stresses $\sigma_{\mathrm{i}, \mathrm{j}}$ and $\tau_{\mathrm{i}, \mathrm{j}}$ according to the cohesive tensile/shear traction - displacement relationships as shown in Fig. 10.

3. Calculate $K_{1}^{\mathrm{P}}, K_{1}^{\sigma, \tau}, K_{2}^{\mathrm{P}}$ and $K_{2}^{\sigma, \tau}$ by adjusting load $P_{\mathrm{i}, \mathrm{j}}=P_{\mathrm{i}-1, \mathrm{j}} \pm \Delta P$ until Eq. (9) is satisfied.

4. Repeat Steps 1 and 3 for the next step of crack propagation.

5. Terminate the iterative process when $a_{\mathrm{i}, \mathrm{j}}$ is equal to the specimen height or $P_{\mathrm{i}, \mathrm{j}} \leq 0$.

By repeating the steps, the complete interface fracture process can be obtained numerically. The parameters used in the simulations included $K_{1}^{\mathrm{ini}}$ and $\mathrm{G}_{\mathrm{If}}$, which have been listed in Tables 1 and 2 . By taking Specimens TPB-5 $\times 5$, C-R-240-3×3, C-R-240-4×4, C-R-235-5×5 and C-R-250-7×7 as examples, Fig. 12 illustrates the comparisons of the numerically predicted $P$-CMOD curves with the experimental data, and fairly good agreements can be observed.

\section{Discussion on Crack Propagation Paths}

As motioned above, three potential propagation paths existed for the pre-crack at the 
rock-concrete interface, which would be governed by the stress conditions in front of the crack tip and the mechanical properties of the concrete, rock and their interface. Generally, the mechanical and fracture properties of the interface were smaller than those for the concrete and rock. Therefore, the crack would propagate along the interface in the mode I dominated fracture. With the increase of $K_{2} / K_{1}$, the crack could branch at the interface and kink into the rock or concrete, even the crack directly initiated in the rock or concrete. To predict the potential crack propagation path, in addition to the criterion for the propagation of the interfacial crack, it is also essential to develop the criterion for the crack to penetrate into the rock or concrete.

In this study, the function for the maximum circumferential stress criterion (Ryoji and Xu 1992,

Kishen and Singh 2001) was employed to determine the kinking of the interfacial crack as follows:

$$
K_{\mathrm{I}, \mathrm{II}}^{*}=\frac{\sqrt{\left(K_{1}^{\mathrm{P}}-K_{1}^{\mathrm{\sigma}, \tau}\right)^{2}+\left(K_{2}^{\mathrm{P}}-K_{2}^{\mathrm{\sigma}, \tau}\right)^{2}}}{2 \cosh (\varepsilon \pi)} W_{\mathrm{j}}\left[2 \cos \left(\frac{\theta_{0}}{2}+\gamma\right)-\left(\cos \theta_{0}+2 \varepsilon \sin \theta_{0}\right) \cos \left(\frac{\theta_{0}}{2}-\gamma\right)\right]+\frac{1}{W_{\mathrm{j}}} \cos \left(\frac{3}{2} \theta_{0}+\gamma\right)=K_{\mathrm{Ij}}^{\mathrm{ini}}
$$

where $K_{\mathrm{Ij}}^{\mathrm{ini}}$ is the initial mode I fracture toughness of material $j, j$ denotes rock or concrete, and $\theta_{0}$ is the kinking angle which can be obtained by solving Eq. (12) numerically

$$
\begin{aligned}
& \varepsilon W_{\mathrm{j}}\left[2 \cos \left(\frac{\theta}{2}+\gamma\right)-(\cos \theta+2 \varepsilon \sin \theta) \cos \left(\frac{\theta}{2}-\gamma\right)\right] \\
& +W_{\mathrm{j}}\left[-\sin \left(\frac{\theta}{2}+\gamma\right)+(\sin \theta-2 \varepsilon \cos \theta) \cos \left(\frac{\theta}{2}-\gamma\right)\right] \\
& +W_{\mathrm{j}}\left[\frac{1}{2}(\cos \theta+2 \varepsilon \sin \theta) \sin \left(\frac{\theta}{2}-\gamma\right)\right]-\frac{1}{W_{\mathrm{j}}}\left[\varepsilon \cos \left(\frac{3}{2} \theta+\gamma\right)+\frac{3}{2} \sin \left(\frac{3}{2} \theta+\gamma\right)\right]=0 \\
& \gamma= \begin{cases}\arctan \left(\left(K_{2}^{\mathrm{P}}-K_{2}^{\mathrm{\sigma}, \tau}\right) /\left(K_{2}^{\mathrm{p}}-K_{2}^{\mathrm{\sigma}, \tau}\right)\right) & K_{1}>0 \\
\pi+\arctan \left(\left(K_{2}^{\mathrm{P}}-K_{2}^{, \sigma, \tau}\right) /\left(K_{2}^{\mathrm{P}}-K_{2}^{, \sigma, \tau}\right)\right) & K_{1}<0\end{cases} \\
& W_{\mathrm{j}}= \begin{cases}e^{-\varepsilon\left(\pi-\theta_{0}\right)} & j=1 \\
e^{\varepsilon\left(\pi+\theta_{0}\right)} & j=2\end{cases}
\end{aligned}
$$

It should be mentioned that the expression for the maximum circumferential stress criterion 
used in this study is different from those in literature (Ryoji and Xu 1992, Kishen and Singh 2001).

327 Instead of the unstable fracture toughness $K_{\mathrm{ICj}}$, the initial fracture toughness $K_{\mathrm{Ij}}^{\mathrm{ini}}$, which is on the 328 right side of Eq. (11) was used to determine the crack initiation. The purpose of the substitution is considering that the crack propagation into the material $j$ still represents the initiation of a new crack rather than the unstable propagation of the existing crack. In addition, Eq. (11) can only be obtained 331 for small $|\varepsilon|$ (Ryoji and Xu 1992). Here, $\varepsilon$ is a material constant shown in Eq. (5). Fortunately, 332 the value of $|\varepsilon|$ for dissimilar composite materials is less than 0.1. For instance, the value of $|\varepsilon|$ for 333 the composite rock-concrete specimens in this study was calculated as 0.0074 , so that the criterion 334 shown in Eq. (11) should be valid. with the criterion equation for the maximum circumferential stress of material $j$, i.e. Eq. (11), the potential propagation of an interfacial crack could be judged in this study as follows:

(i) If $K_{\mathrm{I}, \mathrm{II}}^{*}<K_{\mathrm{Ij}}^{\mathrm{ini}}$ and $K_{1,2}^{*}<K_{1 \mathrm{C}}^{\mathrm{ini}}$, the crack does not propagate;

(ii) If $K_{\mathrm{I}, \mathrm{II}}^{*}<K_{\mathrm{Ij}}^{\mathrm{ini}}$ and $K_{1,2}^{*}>K_{\mathrm{lC}}^{\mathrm{ini}}$, the crack propagates along the interface;

(iii) If $K_{\mathrm{I}, \mathrm{II}}^{*}>K_{\mathrm{Ij}}^{\mathrm{ini}}$ and $K_{1,2}^{*}<K_{1 \mathrm{C}}^{\mathrm{ini}}$, the crack propagates into the material $j$ with a kinking angle $\theta_{0}$.

The above mentioned method can be also used to predict the crack initiation. In this case, only the SIFs caused by the external load, i.e. $K_{1}^{\mathrm{P}}$ and $K_{2}^{\mathrm{P}}$, exist in the expressions for $K_{\mathrm{I}, \mathrm{II}}^{*}$ and $K_{1,2}^{*}$, due to no development of micro-cracks. Therefore, the crack will directly penetrate into the material $j$ if $K_{\mathrm{I}, \mathrm{II}}^{*}>K_{\mathrm{Ij}}^{\mathrm{ini}}$ and $K_{1,2}^{*}<K_{1 \mathrm{C}}^{\mathrm{ini}}$. Under this condition, the fracture analysis transforms into the crack propagation in a homogeneous material under the mixed mode I-II loading, which has been investigated by Wu et al. (2013). 
In addition, the potential crack propagation path could be predicted by applying the criteria for the propagation of the interfacial crack and the maximum circumferential stress. By taking the composite C-R series beams in this study as examples, Fig. 13(a) shows the $K_{1}-K_{2}$ relationships of the criteria with $K_{\mathrm{I}, \mathrm{II}}^{*}=K_{\mathrm{Ij}}^{\mathrm{ini}}$ for the rock and $K_{1,2}^{*}=K_{1 \mathrm{C}}^{\mathrm{ini}}$ for the interface. For the composite C-R series beams under the loading condition as shown in Fig. 1(b), it is impossible for the crack to kink into the concrete so that only the criterion for the interfacial crack propagation and the criterion for the maximum circumferential stress of the rock were assessed. For the criterion for the interfacial crack initiation, i.e. $K_{1,2}^{*}=K_{1 \mathrm{C}}^{\mathrm{ini}}$, there were four curves with respect to the interfaces of four roughness degrees, as illustrated in Fig. 13(a). For the criterion for the maximum circumferential stress of the rock, i.e. $K_{\mathrm{I}, \mathrm{II}}^{*}=K_{\mathrm{Ij}}^{\mathrm{ini}}$ with $j$ representing the rock, there is one curve illustrated in Fig. 13(a). $K_{\mathrm{Ij}}^{\mathrm{ini}}$ for the rock in this study was determined as $1.205 \mathrm{MPa} \cdot \mathrm{m}^{1 / 2}$ by conducting the standard TPB tests on the rock specimens. It can be seen from this figure that the curve for the rock with $K_{\mathrm{I}, \mathrm{II}}^{*}=K_{\mathrm{Ij}}^{\mathrm{ini}}$ is always outside the curves for $K_{1,2}^{*}=K_{1 \mathrm{C}}^{\mathrm{ini}}$. This indicates that under any loading conditions, the crack would not propagate into the rock from the interfaces of the composite C-R specimens with four roughness degrees in this study. This has also been validated by the experimental failure patterns of the composite C-R series beams as shown in Fig. 6. The qualitative assessment is significantly useful for practical constructions, e.g. gravity concrete hydraulic dams, to determine whether propagations of interfacial cracks into rock foundations can be excluded or not.

It should be mentioned that, even though the crack propagated fully along the interface for all composite C-R series beams, there would still exist two different variation tendencies for $K_{2} / K_{1}$ during the complete fracture process. One is that the ratio $K_{2} / K_{1}$ would always increase as the interfacial crack propagated, and another is that the ratio would always decrease correspondingly. 
Based on the numerical simulation results, it is found that there was a critical value for the mode mixity ratio $K_{2} / K_{1}$ when the material and interface properties were given. This critical mode mixity ratio was equal to 0.788 for the materials adopted in this study. The points for four toughness degrees corresponding to the critical mode mixity ratio are illustrated in Fig. 13(a) as A, B, C and D, respectively. When the ratio $K_{2}^{\mathrm{ini}} / K_{1}^{\mathrm{ini}}$ was less than the critical value, the ratio $K_{2} / K_{1}$ would always decrease as the crack propagated so that the fracture became mode I dominated. In contrast, when the ratio $K_{2}^{\text {ini }} / K_{1}^{\text {ini }}$ was greater than the critical value, the ratio $K_{2} / K_{1}$ would always increase as the crack propagated and the fracture became mode II dominated. Fig. 13(a) also shows the variations of $K_{2} / K_{1}$ during the crack propagation for the C-R-235 series specimens with $K_{2}^{\text {ini }} / K_{1}^{\text {ini }}=0.718<0.788$ (see the solid symbols in Fig. 13(a)), and for the C-R-245 series specimens with $K_{2}^{\mathrm{ini}} / K_{1}^{\mathrm{ini}}=2.275>0.788$ (see the hollow symbols). This clearly illustrates the variation tendencies of $K_{2} / K_{1}$ for the specimens with different values of $K_{2}^{\text {ini }} / K_{1}^{\text {ini }}$ during the complete fracture process.

Although the interfacial crack does not propagate into the rock based on the criterion comparisons in Fig. 13(a), the propagation path of the interfacial crack can still not be defined if the positions of the rock and concrete are exchanged. In this case, the relationship between the criterion for the maximum circumferential stress of the concrete and the criterion for the propagation of the interfacial crack should be evaluated. The curves for the criteria with $K_{\mathrm{I}, \mathrm{II}}^{*}=K_{\mathrm{Ij}}^{\mathrm{ini}}$ and $K_{1,2}^{*}=K_{1 \mathrm{C}}^{\mathrm{ini}}$ are shown in Fig. 13(b), where $j$ denotes the concrete material. For the criterion with $K_{1,2}^{*}=K_{1 \mathrm{C}}^{\mathrm{ini}}$, the curves with respect to two toughness degrees $\left(R_{\mathrm{a}}=0.963\right.$ and $K_{1 \mathrm{C}}^{\mathrm{ini}}=0.399 ; R_{\mathrm{a}}=1.183$, $\left.K_{\mathrm{lC}}^{\mathrm{ini}}=0.450\right)$ are illustrated as examples. For the criterion with $K_{\mathrm{I}, \mathrm{II}}^{*}=K_{\mathrm{Ij}}^{\mathrm{ini}}, K_{\mathrm{Ij}}^{\mathrm{ini}}$ for the concrete was determined as $0.55 \mathrm{MPam}^{1 / 2}$ from the standard TPB tests on the concrete specimens. Compared 
with the curves in Fig. 13(a), the criterion curve for the interface intersected with the curve for the concrete in Fig. 13(b). The intersection points corresponded to different $K_{2} / K_{1}$ ratios, i.e. $P_{\mathrm{C}}=0.764$ $\left(R_{\mathrm{a}}=0.963\right.$ and $\left.K_{1 \mathrm{C}}^{\mathrm{ini}}=0.399\right)$ and $Q_{\mathrm{C}}=0.509\left(R_{\mathrm{a}}=1.183\right.$ and $\left.K_{1 \mathrm{C}}^{\mathrm{ini}}=0.450\right)$. This indicates that the interfacial crack would directly initiate and propagate into concrete when $K_{2}^{\mathrm{ini}} / K_{1}^{\mathrm{ini}}>0.764$ for $R_{\mathrm{a}}$ $=0.963$ and $K_{2}^{\mathrm{ini}} / K_{1}^{\mathrm{ini}}>0.509$ for $R_{\mathrm{a}}=1.183$. In contrast, the interfacial crack would initiate and propagate along the interface when $K_{2}^{\mathrm{ini}} / K_{1}^{\mathrm{ini}}<0.764$ for $R_{\mathrm{a}}=0.963$ and $K_{2}^{\mathrm{ini}} / K_{1}^{\mathrm{ini}}<0.509$ for $R_{\mathrm{a}}$ concrete after propagating along the interface. Based on the previous investigations, the variations in $K_{2} / K_{1}$ in the case of interfacial propagation were determined by the critical mode mixty ratio, which are marked as Points B and $\mathrm{C}$ in Fig. 13(b). The intersection points $Q_{\mathrm{C}}$ and $P_{\mathrm{C}}$ are on the left of the critical points $\mathrm{C}$ and $\mathrm{B}$, respectively. It indicates that, in the cases of $K_{2}^{\mathrm{ini}} / K_{1}^{\mathrm{ini}}<0.764$ (Point $Q_{\mathrm{C}}$ ) for $R_{\mathrm{a}}=0.963$ and $K_{2}^{\mathrm{ini}} / K_{1}^{\mathrm{ini}}<0.509$ (Point $P_{\mathrm{C}}$ ) for $R_{\mathrm{a}}=1.183$, the $K_{2} / K_{1}$ ratio would increase as the interfacial crack propagates so that it would not propagate into the concrete under this condition. geometric properties of the R-C series specimens are shown in Fig. 14. It should be noted that, and 0.696 for $R_{\mathrm{a}}=0.963$, and 0.531 and 0.437 for $R_{\mathrm{a}}=1.183$ (see Table 4). The corresponding points are denoted as $P_{2}, P_{1}, Q_{2}$ and $Q_{1}$ in Fig. 13(b), respectively. The experimental design ensured that the 
414 same $R_{\mathrm{a}}$. The experimental results are listed in Table 4. For the R-C series specimens, the initiation and propagation of the crack in the concrete were observed on Specimens R-C-264-4×4 (Point $P_{2}$ with $K_{2}^{\mathrm{ini}} / K_{1}^{\mathrm{ini}}=0.788$ ) and R-C-271-5 $\times 5$ (Point $Q_{2}$ with $K_{2}^{\mathrm{ini}} / K_{1}^{\mathrm{ini}}=0.531$ ), which is denoted as the failure mode $\mathrm{K}$ in Table 4. Correspondingly, the crack propagations fully along the interface were observed on Specimens R-C-266-4×4 (Point $P_{1}$ with $\left.K_{2}^{\mathrm{ini}} / K_{1}^{\mathrm{ini}}=0.696\right)$ and R-C-275-5×5 (Point $Q_{1}$ of $\left.K_{2}^{\mathrm{ini}} / K_{1}^{\mathrm{ini}}=0.437\right)$, which is denoted as the failure mode I. Fig. 15 shows the failure mode with 420 the initiation and propagation of the crack into the concrete. By taking Specimen $\mathrm{R}-\mathrm{C}-264-4 \times 4$ as an example, Figs. 16(a) and (b) illustrate the comparison of the $P$-CMOD curves and the crack propagation trajectories between the experimental and numerical results, respectively, and reasonably good agreements can be observed.

The investigations in this study indicate that the crack propagation mode under different stress conditions could be predicted by combining Eqs. (9) and (11). The application of the proposed concrete materials and their interface would be required in these two equations. Particularly, the three initial fracture toughnesses are relatively easily obtained from the experiment (Dong et al. 2013, Dong et al. 2016c). Once the curves for Eqs. (9) and (11) are obtained, therefore, the failure mode for a mass concrete structure on the rock foundation can be approximately assessed according the loading conditions. However, it should be noted that the further work is still needed to investigate whether Eq. (9) is appropriate for concretes and rocks with various strengths and compositions.

\section{Conclusions}

To study the propagation process of the rock-concrete interfacial crack, an expression for the 
initiation of the interfacial crack has been derived from the experimental investigations. By taking into account the nonlinear characteristics of the interface between two different materials, a criterion

438 for the crack propagation has been proposed to envisage the propagation of a crack along the interface. Based on the criterion for the maximum circumferential stress and the proposed criterion in this study, the interfacial fracture modes, including propagating of a crack along the interface and kinking into the rock or concrete, can be predicted by analyzing the verification curves for these two criteria simultaneously. According to the comprehensive experimental and numerical investigations, the following conclusions can be drawn:

444 1. For the rock-concrete interfaces with four different roughness profiles investigated in this study, a universal expression for predicting the initiation of a crack along the interface has been obtained by normalizing their initial fracture toughnesses. Also, a criterion for the propagation of the crack has been proposed based on the expression for the crack initiation by introducing the fictitious crack model. This criterion has been verified by comparing the $P-C M O D$ curves obtained numerically and experimentally, and fairly good agreements have been observed. However, further work should be conducted to verify the validity of the universal expression for the initiation of a crack at the interfaces between concrete and rock of different properties and compositions.

2. The proposed criterion for the propagation of the interfacial crack can be utilized to predict the complete interfacial fracture process for the mixed mode I-II fracture. By applying the fictitious cracking model, the nonlinear characteristics of the interface have been considered in the criterion. This has been verified by comparing the $P$-CMOD curves obtained from the experimental investigations and numerical simulations. For propagation of the crack along the 
interface, there exists a critical mode mixty ratio, which has been determined as 0.788 for the materials used in this study. When the $K_{2}^{\mathrm{ini}} / K_{1}^{\mathrm{ini}}$ ratio was greater than the critical mode mixty ratio, $K_{2} / K_{1}$ would increase as the interfacial crack propagated. In contrast, when the $K_{2}^{\mathrm{ini}} / K_{1}^{\mathrm{ini}}$ ratio was less than the critical mixty ratio, the $K_{2} / K_{1}$ ratio would decrease as the interfacial crack

3. Crack propagation paths, i.e. developing along the interface or kinking into the rock or concrete, could be predicted by analyzing the curves for the criterion for the interfacial crack propagation and the criterion for the crack to kink into the rock or concrete. If the curve for the interfacial criterion was inside the curve for the kinking criterion for the rock or concrete, the crack would always propagate along the interface. In contrast, if there was an intersection point between two criteria, the interfacial crack would either propagate along the interface or penetrate into rock or concrete, depending on the relationship between the $K_{2}^{\text {ini }} / K_{1}^{\text {ini }}$ ratio and the $K_{2} / K_{1}$ ratio corresponding to the intersection point.

4. The criteria for propagating and kinking of the interfacial crack into the rock or concrete could be determined by obtaining the initial fracture toughnesses of the rock, concrete and their interface. Actually, these values could be conveniently derived by measuring the initial fracture load from the TPB tests.

\section{Acknowledgements}

The financial support of the National Natural Science Foundation of China under the grants of NSFC 51478083, NSFC 51421064 and NSFC 51109026, the Fundamental Research Funds for the Central Universities of China under the grants of DUT17LK06, and the Natural Science Foundation 
of Liaoning Province of China under the grant of 20170540183 is gratefully acknowledged.

\section{References}

Bažant, Z. P., M. R. Tabbara, M. T. Kazemi and G. Pijaudier-Cabot (1990). "Random particle model for fracture of aggregate or fiber composites." J. Eng. Mech., 116(8), 1686-1705.

Červenka, J., J. C. Kishen and V. E. Saouma (1998). "Mixed mode fracture of cementitious bimaterial interfaces: Part II Numerical simulation." Eng. Fract. Mech., 60(1), 95-107.

Cusatis, G., Z. P. Bažant and L. Cedolin (2003a). "Confinement-shear lattice model for concrete damage in tension and compression: II. Computation and validation." J. Eng. Mech., 129(12), $1449-1458$.

Cusatis, G., Z. P. Bažant and L. Cedolin (2003b). "Confinement-shear lattice model for concrete damage in tension and compression: I. Theory." J. Eng. Mech., 129(12), 1439-1448.

Cusatis, G., Z. P. Bažant and L. Cedolin (2006). "Confinement-shear lattice CSL model for fracture propagation in concrete." Computer Methods in Applied Mechanics and Engineering, 195(52), 7154-7171.

Cusatis, G., A. Mencarelli, D. Pelessone and J. Baylot (2011a). "Lattice discrete particle model (LDPM) for failure behavior of concrete. II: Calibration and validation." Cement and Concrete composites, 33(9), 891-905.

Cusatis, G., D. Pelessone and A. Mencarelli (2011b). "Lattice discrete particle model (LDPM) for failure behavior of concrete. I: Theory." Cement and Concrete Composites, 33(9), 881-890.

Dong, W., Z. Wu and X. Zhou (2013). "Calculating crack extension resistance of concrete based on a new crack propagation criterion." Constr. Build. Mater., 38, 879-889.

Dong, W., D. Yang, X. Zhou, G. Kastiukas and B. Zhang (2016a). "Experimental and numerical investigations on fracture process zone of rock-concrete interface." Fatigue Fract. Eng. M. (in press).

Dong, W., Z. Wu, X. Zhou, N. Wang and G. Kastiukas (2016b). "An experimental study on crack propagation at rock-concrete interface using digital image correlation technique." Eng. Fract. Mech. (in press).

Dong, W., Z. Wu and X. Zhou (2016c). "Fracture mechanisms of rock-concrete interface: experimental and numerical." J. Eng. Mech., 142(7), 04016040. 
521 Hillerborg, A., M. Modéer and P.-E. Petersson (1976). "Analysis of crack formation and crack 522 growth in concrete by means of fracture mechanics and finite elements." Cem. Conc. Res., 6(6), $523 \quad 773-781$.

524

525

526

527

528

529

530

531

532

533

534

535

536

537

538

539

540

541

542

543

544

545

546

547

548

549

550

551

552

553

554

555

556

557

558

559

560

561

562

563

564

Kishen, J. C. and K. D. Singh (2001). "Stress intensity factors based fracture criteria for kinking and branching of interface crack: application to dams." Eng. Fract. Mech., 68(2), 201-219.

Moës, N. and T. Belytschko (2002). "Extended finite element method for cohesive crack growth." Eng. Fract. Mech., 69(7), 813-833.

Nagashima, T., Y. Omoto and S. Tani (2003). "Stress intensity factor analysis of interface cracks using X-FEM." Int. J. for Num. Methods in Eng., 56(8), 1151-1173.

Qian, W. and C. Sun (1998). "Methods for calculating stress intensity factors for interfacial cracks between two orthotropic solids." Int. J. Solids Struct., 35(25), 3317-3330.

Ryoji, Y. and J.-Q. Xu (1992). "Stress based criterion for an interface crack kinking out of the interface in dissimilar materials." Eng. Fract. Mech., 41(5), 635-644.

Slowik, V., J. C. Kishen and V. E. Saouma (1998). "Mixed mode fracture of cementitious bimaterial interfaces: Part I Experimental results." Eng. Fract. Mech., 60(1), 83-94.

Sujatha, V. and J. C. Kishen (2003). "Energy release rate due to friction at bimaterial interface in dams." J. Eng. Mech., 129(7), 793-800.

Wu, Z., H. Rong, J. Zheng and W. Dong (2013). "Numerical method for mixed-mode I-II crack propagation in concrete." J. Eng. Mech., 139(11), 1530-1538.

Xu, S. and H. W. Reinhardt (1999a). "Determination of double-K criterion for crack propagation in quasi-brittle fracture: Part I Experimental investigation of crack propagation." Int. J. Fract., 98(2), 111-149.

$\mathrm{Xu}, \mathrm{S}$. and H. W. Reinhardt (1999b). "Determination of double-K criterion for crack propagation in quasi-brittle fracture: Part II Analytical evaluating and practical measuring methods for three-point bending notched beams." Int. J. Fract., 98(2), 151-177.

Yang, S., L. Song, Z. Li and S. Huang (2008). "Experimental investigation on fracture toughness of interface crack for rock/concrete." Int. J. Mod. Phys. B, 22(31/32), 6141-6148.

Zhong, H., E. T. Ooi, C. Song, T. Ding, G. Lin and H. Li (2014). "Experimental and numerical study of the dependency of interface fracture in concrete-rock specimens on mode mixity." Eng. Fract. Mech., 124, 287-309. 
Tables

566

567

\begin{tabular}{ccccccccc}
\hline Series & $\begin{array}{c}E \\
(\mathrm{GPa})\end{array}$ & $\begin{array}{c}\rho \\
\left(\mathrm{g} / \mathrm{cm}^{3}\right)\end{array}$ & $v$ & $\begin{array}{c}f_{\mathrm{t}} \\
(\mathrm{MPa})\end{array}$ & $\begin{array}{c}f_{\mathrm{c}} \\
(\mathrm{MPa})\end{array}$ & $\begin{array}{c}R_{\mathrm{a}} \\
(\mathrm{mm})\end{array}$ & $\begin{array}{c}K_{\mathrm{I}}^{\mathrm{ini}} \\
\left(\mathrm{MPa} \cdot \mathrm{m}^{1 / 2}\right)\end{array}$ & $\begin{array}{c}G_{\text {If }} \\
(\mathrm{N} / \mathrm{m})\end{array}$ \\
\hline Concrete & 32.86 & 2.45 & 0.256 & 2.200 & 37.20 & & 0.550 & 101.91 \\
Rock & 41.17 & 2.75 & 0.173 & - & 142.00 & & 1.205 & 135.38 \\
Interface $(3 \times 3)$ & - & - & - & 1.170 & - & 0.780 & - & - \\
Interface $(4 \times 4)$ & - & - & - & 1.391 & - & 0.963 & - & - \\
Interface $(5 \times 5)$ & - & - & - & 1.659 & - & 1.183 & - & - \\
Interface $(7 \times 7)$ & - & - & - & 2.101 & - & 1.548 & - & - \\
\hline
\end{tabular}

Table 2 Experimental results of the TPB tests ${ }^{2}$

\begin{tabular}{|c|c|c|c|c|c|c|c|}
\hline Specimen & $\begin{array}{c}P_{\text {ini }} \\
(\mathrm{kN})\end{array}$ & $\begin{array}{l}P_{\max } \\
(\mathrm{kN})\end{array}$ & $\begin{array}{c}K_{1}^{\mathrm{ini}} \\
\left(\mathrm{MPa} \cdot \mathrm{m}^{1 / 2}\right)\end{array}$ & $\begin{array}{c}K_{2}^{\mathrm{ini}} \\
\left(\mathrm{MPa} \cdot \mathrm{m}^{1 / 2}\right)\end{array}$ & $\left|K_{2}^{\mathrm{ini}} / K_{1}^{\mathrm{ini}}\right|$ & $\begin{array}{c}R_{\mathrm{a}} \\
(\mathrm{mm})\end{array}$ & $\begin{array}{c}G_{\text {If }} \\
(\mathrm{N} / \mathrm{m})\end{array}$ \\
\hline TPB-3×3 & 1.720 & 1.825 & 0.351 & -0.019 & 0.055 & 0.780 & 9.25 \\
\hline ТPB- $4 \times 4$ & 1.965 & 2.234 & 0.399 & -0.022 & 0.055 & 0.963 & 18.98 \\
\hline ТPB $-5 \times 5$ & 2.210 & 2.623 & 0.450 & -0.025 & 0.055 & 1.183 & 22.72 \\
\hline ТРВ $-7 \times 7$ & 2.385 & 2.816 & 0.483 & -0.026 & 0.055 & 1.548 & 30.14 \\
\hline
\end{tabular}

$573 \quad{ }^{2} P_{\text {ini }}-$ Initial cracking load; $P_{\max }-$ Peak load; $K_{1}^{\text {ini }}-$ Initial fracture toughness of mode $1 ; K_{2}^{\text {ini }}-$ Initial fracture

574 toughness of mode $2 ; R_{\mathrm{a}}$ - Degree of roughness; $G_{\mathrm{If}}-$ Fracture energy. 
Table 3 Experimental results of the C-R series beams under FPS ${ }^{3}$.

\begin{tabular}{|c|c|c|c|c|c|c|c|c|}
\hline Specimen & $\begin{array}{c}L_{\mathrm{R}} \\
(\mathrm{mm}) \\
\end{array}$ & $\begin{array}{c}P_{\text {ini }} \\
(\mathrm{kN}) \\
\end{array}$ & $\begin{array}{l}P_{\max } \\
(\mathrm{kN})\end{array}$ & $\begin{array}{c}K_{1}^{\mathrm{ini}} \\
\left(\mathrm{MPa} \cdot \mathrm{m}^{1 / 2}\right)\end{array}$ & $\begin{array}{c}K_{2}^{\mathrm{ini}} \\
\left(\mathrm{MPa} \cdot \mathrm{m}^{1 / 2}\right)\end{array}$ & $\left|K_{2}^{\mathrm{ini}} / K_{1}^{\mathrm{ini}}\right|$ & $\begin{array}{c}R_{\mathrm{a}} \\
(\mathrm{mm})\end{array}$ & $\begin{array}{c}\text { Failure } \\
\text { mode }\end{array}$ \\
\hline C-R-225-3×3 & 225 & 12.860 & 14.947 & 0.399 & 0.143 & 0.359 & & I \\
\hline C-R-235-3×3 & 235 & 14.136 & 18.813 & 0.298 & 0.215 & 0.723 & & I \\
\hline C-R-240-3×3 & 240 & 22.000 & 22.545 & 0.334 & 0.381 & 1.138 & 0.780 & I \\
\hline C-R-245-3×3 & 245 & 27.065 & 27.865 & 0.232 & 0.528 & 2.275 & & I \\
\hline C-R-250-3×3 & 250 & 27.500 & 37.087 & 0.036 & 0.606 & 16.595 & & I \\
\hline C-R-225-4×4 & 225 & 13.405 & 15.355 & 0.416 & 0.149 & 0.358 & & I \\
\hline C-R-235-4×4 & 235 & 17.080 & 20.687 & 0.361 & 0.260 & 0.719 & & I \\
\hline C-R-240-4×4 & 240 & 23.990 & 27.050 & 0.365 & 0.415 & 1.136 & 0.963 & I \\
\hline C-R-245-4×4 & 245 & 28.898 & 33.390 & 0.248 & 0.564 & 2.270 & & I \\
\hline C-R-250-4×4 & 250 & 33.208 & 39.957 & 0.046 & 0.732 & 15.973 & & $\mathrm{IC}$ \\
\hline C-R-225-5×5 & 225 & 16.733 & 20.283 & 0.521 & 0.186 & 0.357 & & I \\
\hline C-R-235-5×5 & 235 & 15.743 & 24.233 & 0.332 & 0.240 & 0.721 & & I \\
\hline C-R-240-5×5 & 240 & 22.767 & 31.007 & 0.346 & 0.394 & 1.137 & 1.183 & I \\
\hline C-R-245-5×5 & 245 & 25.580 & 28.057 & 0.219 & 0.500 & 2.280 & & I \\
\hline C-R-250-5×5 & 250 & 30.457 & 41.489 & 0.041 & 0.671 & 16.238 & & I \\
\hline C-R-225-7×7 & 225 & 20.013 & 23.480 & 0.625 & 0.222 & 0.356 & & I \\
\hline C-R-235-7×7 & 235 & 22.887 & 24.317 & 0.486 & 0.348 & 0.715 & & I \\
\hline C-R-240-7×7 & 240 & 26.467 & 27.620 & 0.404 & 0.457 & 1.133 & 1.548 & I \\
\hline C-R-245-7×7 & 245 & 34.400 & 34.930 & 0.297 & 0.671 & 2.258 & & I \\
\hline C-R-250-7×7 & 250 & 34.339 & 39.770 & 0.048 & 0.756 & 15.878 & & IC \\
\hline
\end{tabular}

$578{ }^{3} L_{\mathrm{R}}-$ Length of the rock block; $P_{\text {ini }}-$ Initial cracking load; $P_{\max }-$ Peak load; $K_{1}^{\text {ini }}-$ Initial fracture toughness of

579 mode $1 ; K_{2}^{\text {ini }}$ - Initial fracture toughness of mode 2; $R_{\mathrm{a}}$ - Degree of roughness; Failure mode "I" - Interfacial crack

580 propagates through the interface; Failure mode "IC" - Sudden brittle failure near the supports at the same time

581 when the interfacial crack propagates through the whole interface.

Table 4 Experimental results of the R-C series beams under FPS ${ }^{4}$.

\begin{tabular}{ccccccccc}
\hline Specimen & $\begin{array}{c}L_{\mathrm{R}} \\
(\mathrm{mm})\end{array}$ & $\begin{array}{c}P_{\text {ini }} \\
(\mathrm{kN})\end{array}$ & $\begin{array}{c}P_{\max } \\
(\mathrm{kN})\end{array}$ & $\begin{array}{c}K_{1}^{\text {ini }} \\
\left(\mathrm{MPa} \cdot \mathrm{m}^{1 / 2}\right)\end{array}$ & $\begin{array}{c}K_{2}^{\text {ini }} \\
\left(\mathrm{MPa} \cdot \mathrm{m}^{1 / 2}\right)\end{array}$ & $\left|K_{2}^{\text {ini }} / K_{1}^{\text {ini }}\right|$ & $\begin{array}{c}R_{\mathrm{a}} \\
(\mathrm{mm})\end{array}$ & $\begin{array}{c}\text { Failure } \\
\text { mode }\end{array}$ \\
\hline R-C-264-4×4 & 264 & 17.737 & 22.300 & 0.360 & 0.284 & 0.788 & 0.963 & $\mathrm{~K}$ \\
R-C-266-4×4 & 266 & 17.461 & 20.360 & 0.394 & 0.274 & 0.696 & & $\mathrm{I}$ \\
R-C-271-5 $\times 5$ & 271 & 13.552 & 16.710 & 0.378 & 0.201 & 0.531 & 1.183 & $\mathrm{~K}$ \\
R-C-275-5 $\times 5$ & 275 & 12.640 & 13.380 & 0.404 & 0.176 & 0.437 & $\mathrm{I}$ \\
\hline
\end{tabular}

${ }^{4} L_{\mathrm{R}}-$ Length of the rock block; $P_{\text {ini }}-$ Initial cracking load; $P_{\max }-$ Peak load; $K_{1}^{\text {ini }}-$ Initial fracture toughness of mode $1 ; K_{2}^{\mathrm{ini}}-$ Initial fracture toughness of mode 2; $R_{\mathrm{a}}$ - Degree of roughness; Failure mode "I" - Propagation of the interfacial crack through the interface; Failure mode "K" - Initiation and propagation of the crack in the concrete. 
603

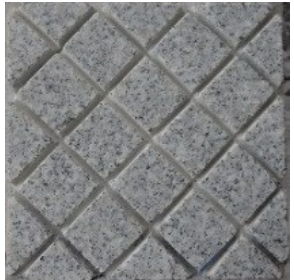

(a) $3 \times 3$

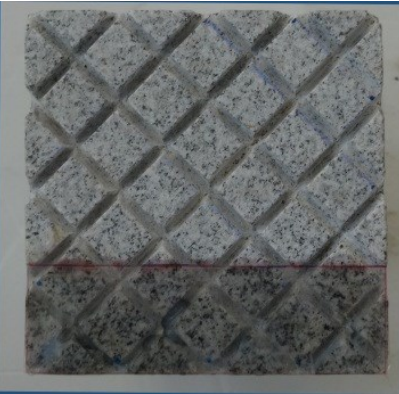

(a) PVC film 1 pasted on the rock

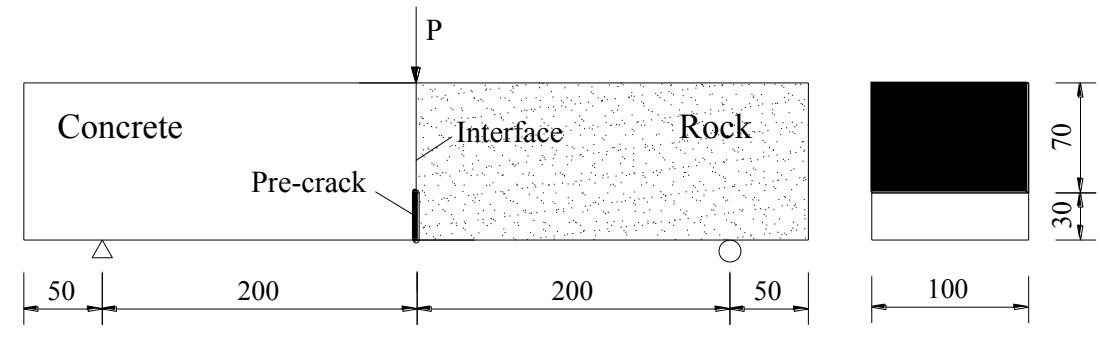

(a) Under three-point bending (TPB)
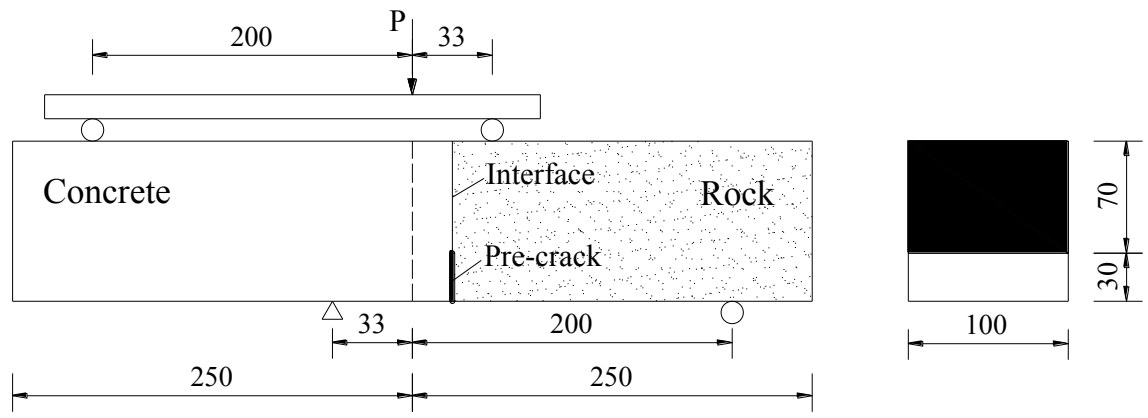

(b) Under four-point shear (FPS)

Fig. 1. Geometries of TPB and C-R series specimens for TPB and FPS fracture tests

Fig. 2. Preparation of the pre-crack
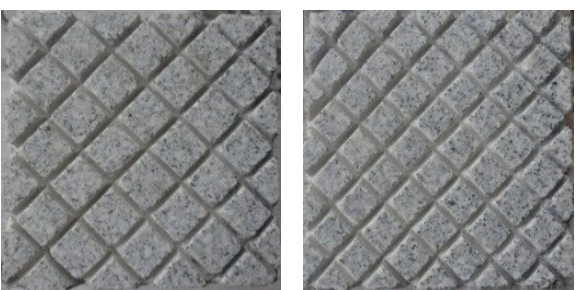

(b) $4 \times 4$

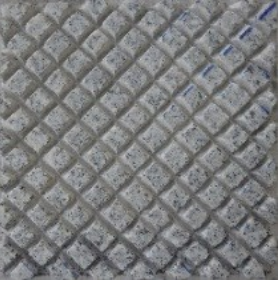

(d) $7 \times 7$

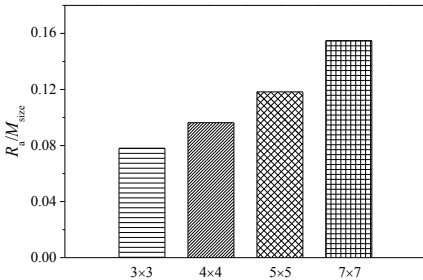

(e) $R_{\mathrm{a}} / M_{\text {size }}$

Fig. 3. Features of rock surfaces at the interface 


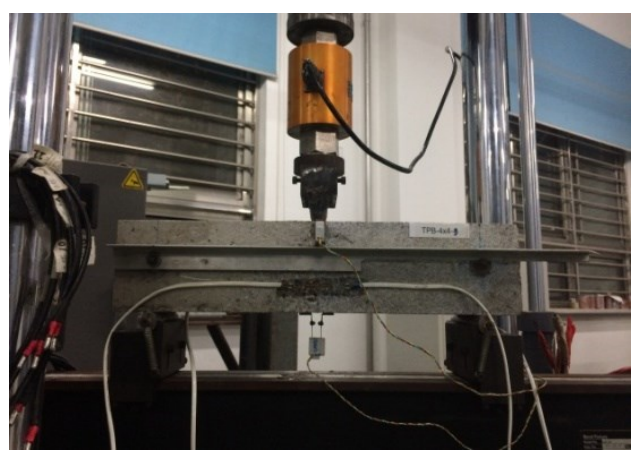

(a) TPB test

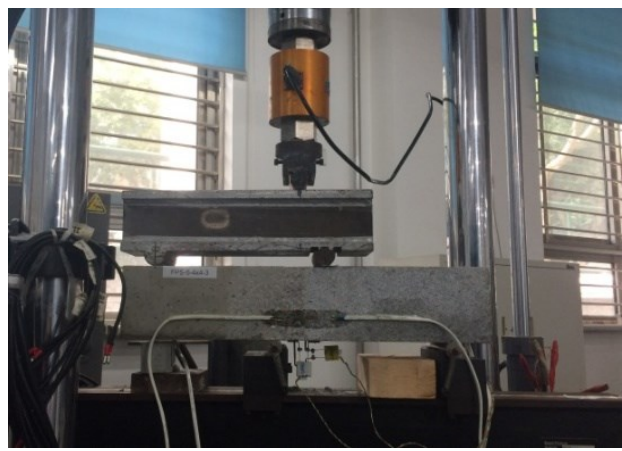

(b) FPS test

Fig. 4. Experimental setups

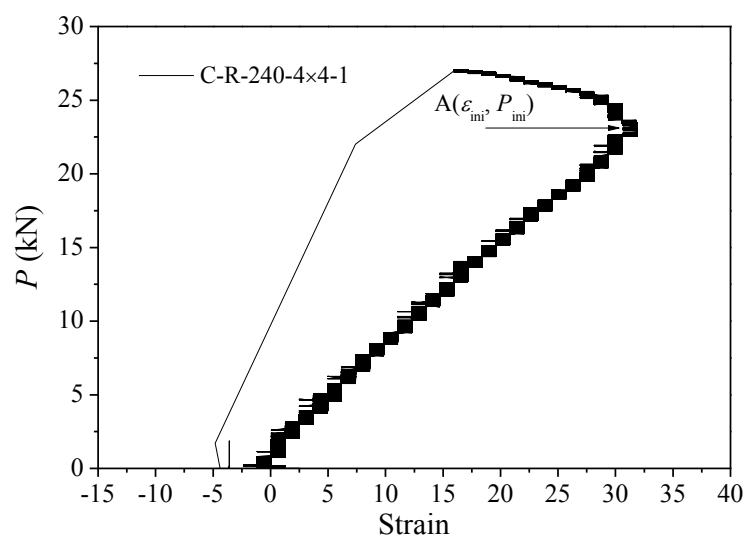

Fig. 5. Load versus strain curve for Specimen C-R-240-4×4-1

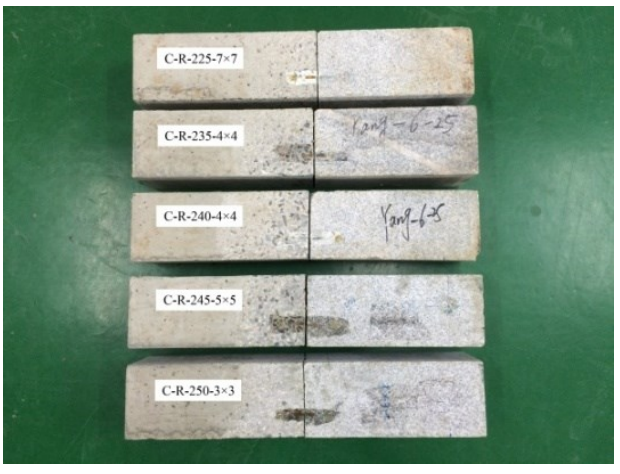

(a) Failure mode I

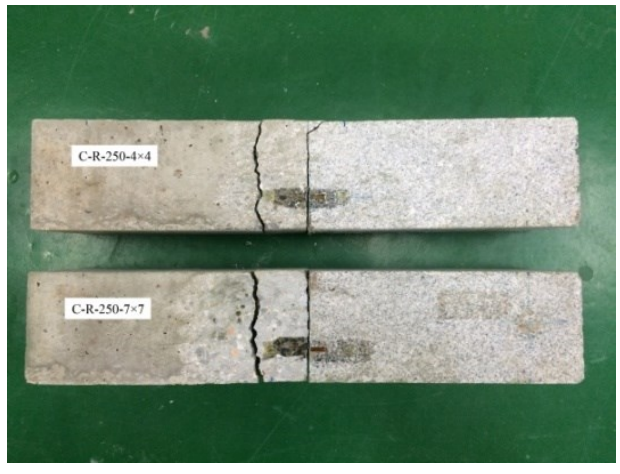

(b) Failure mode IC

Fig. 6. Failure modes of C-R series specimens under FPS 


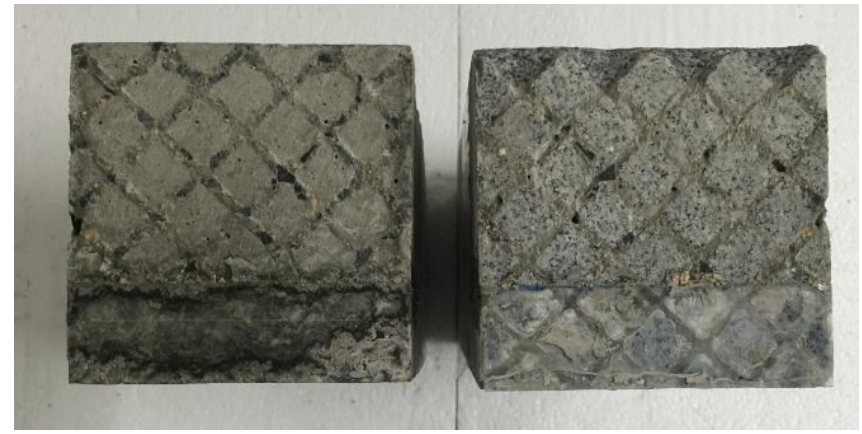

Fig. 7. Cross-section of the specimen under interfacial failure

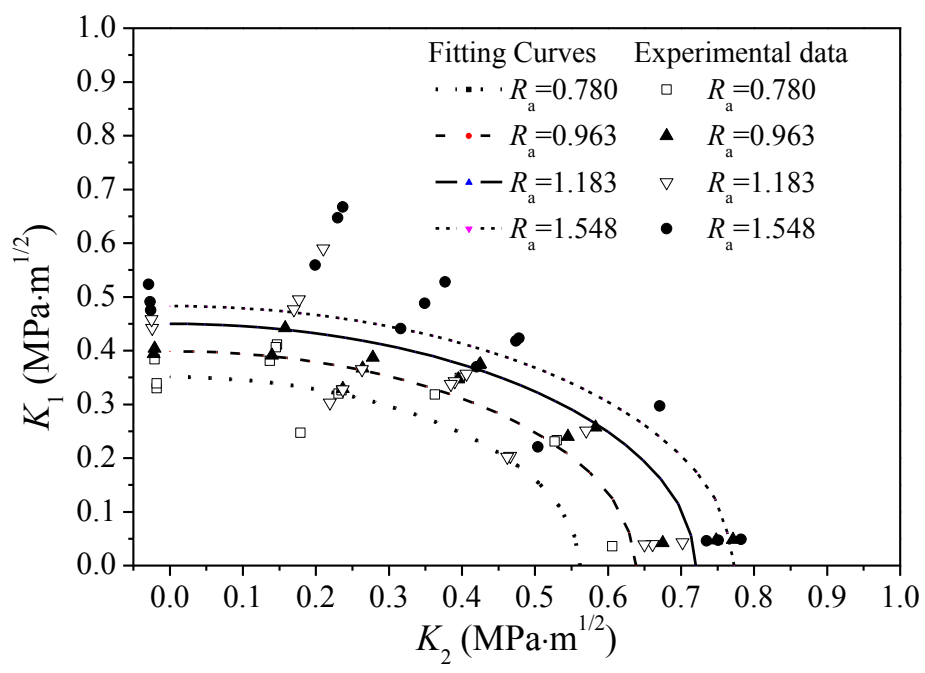

Fig. 8. $K_{1}$ versus $K_{2}$ relationships for interface crack initiation at four roughness degrees

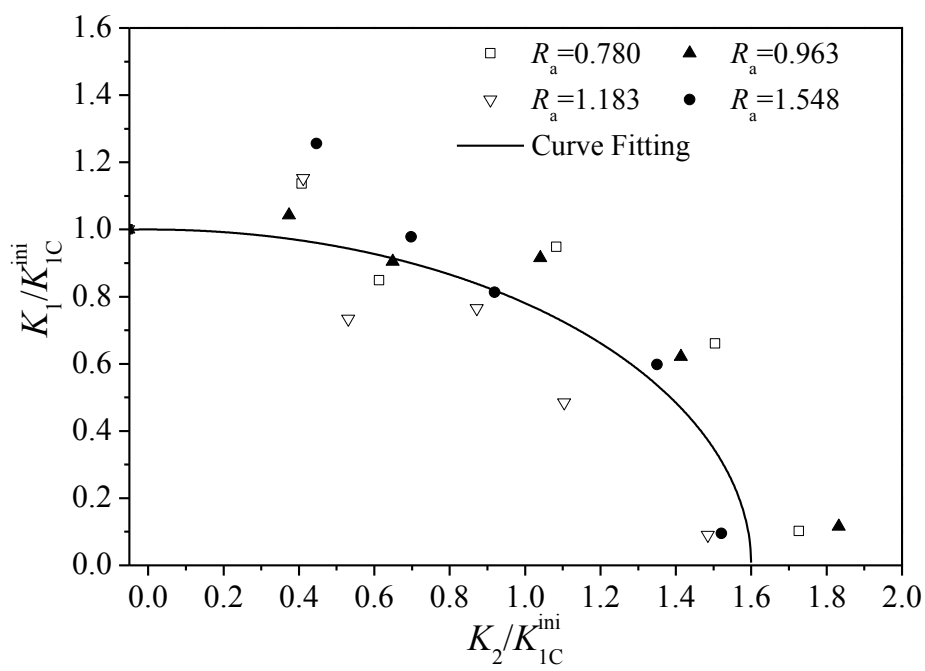

Fig. 9. Normalised $K_{1}$ versus $K_{2}$ relationships at interface crack initiation 


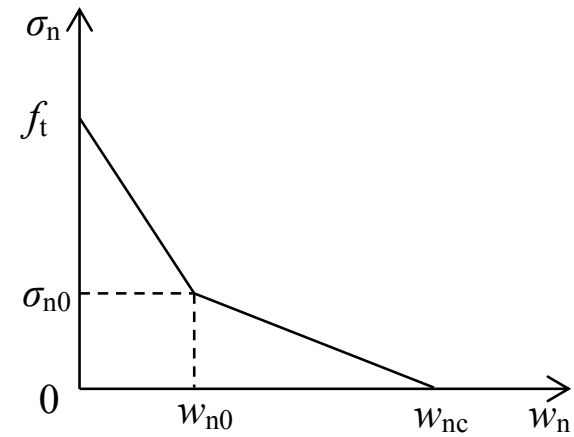

(a) Tension softening relationship

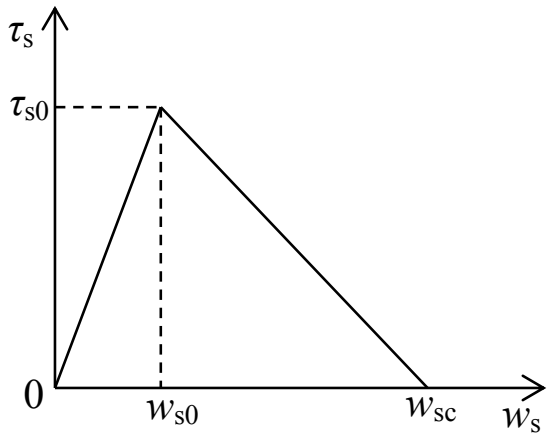

(b) Shear softening relationship

Fig. 10. Cohesive tensile/shear stress versus displacement relationships 628

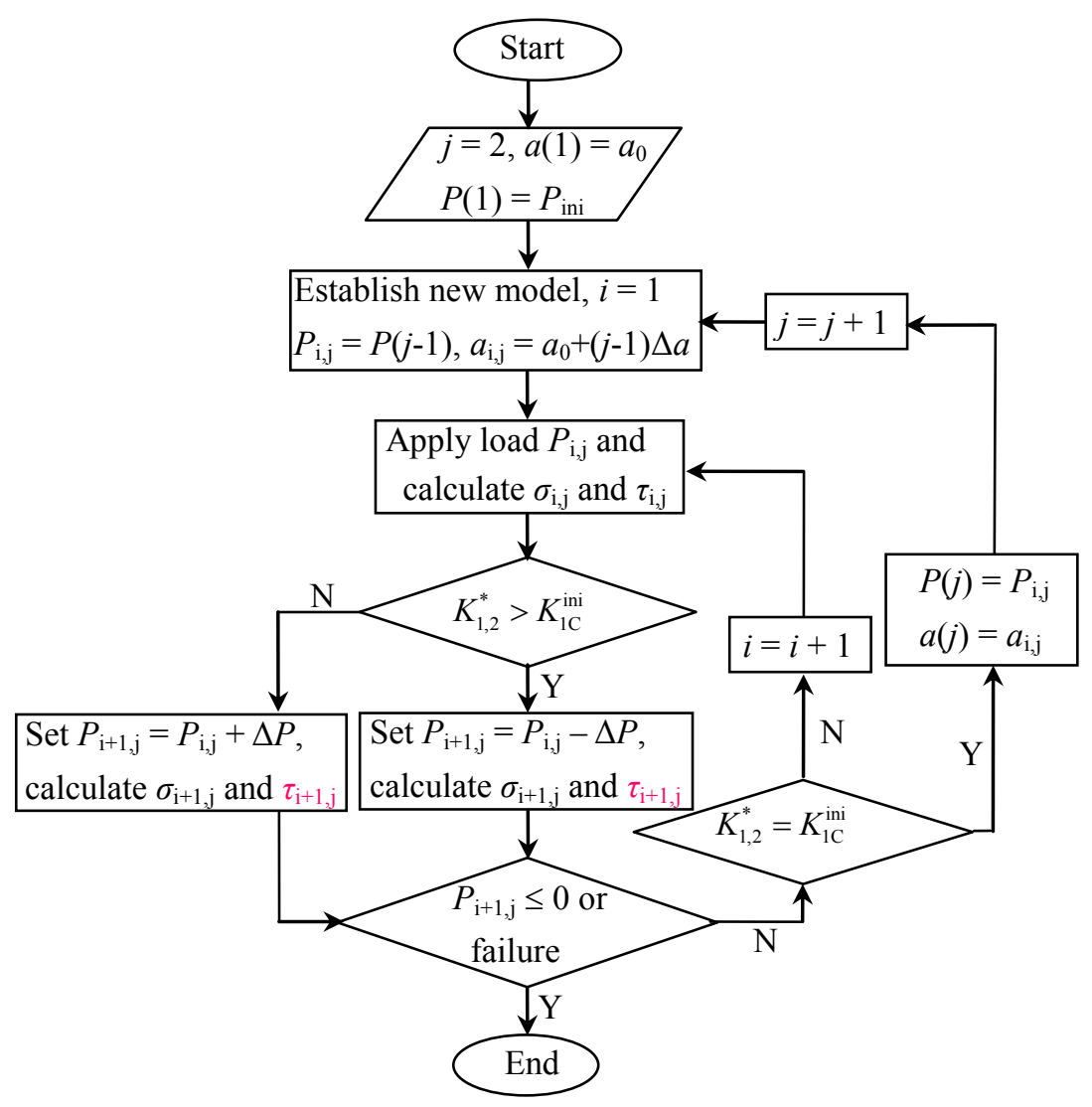

Fig. 11. Flow chart for numerical simulations 
633

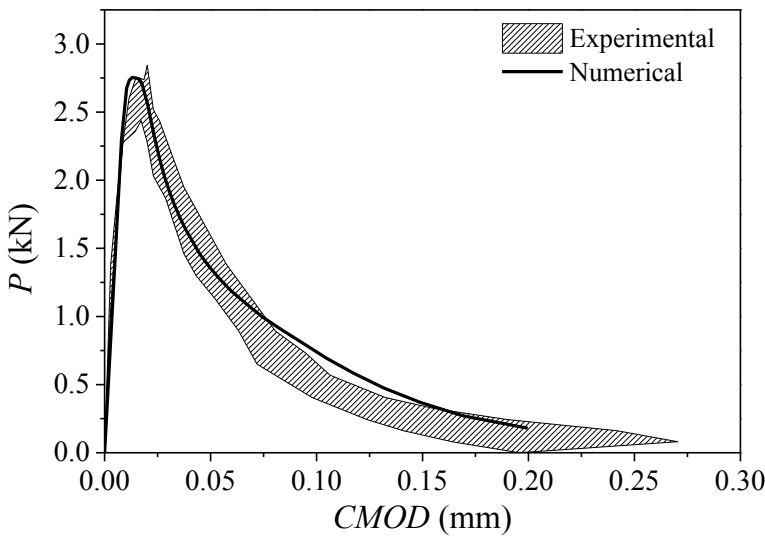

(a) Specimen TPB-5×5

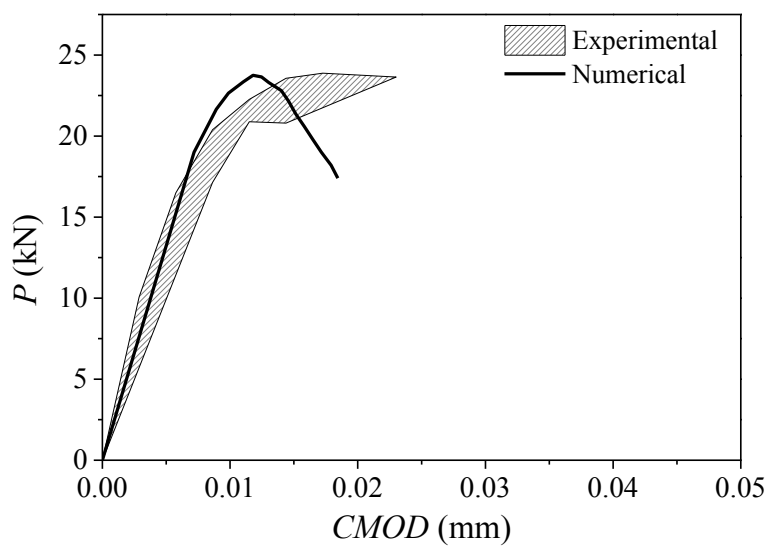

(b) Specimen C-R-240-3×3

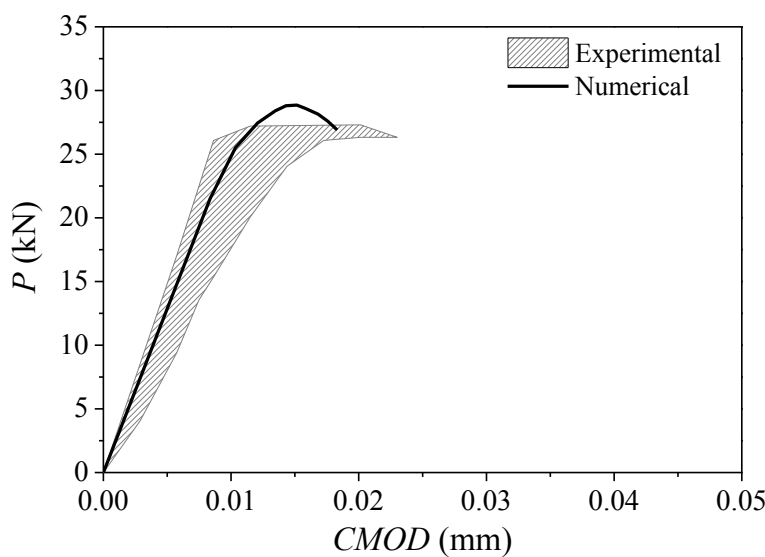

(c) Specimen C-R-240-4×4 
640

641

642

643

644

645

646

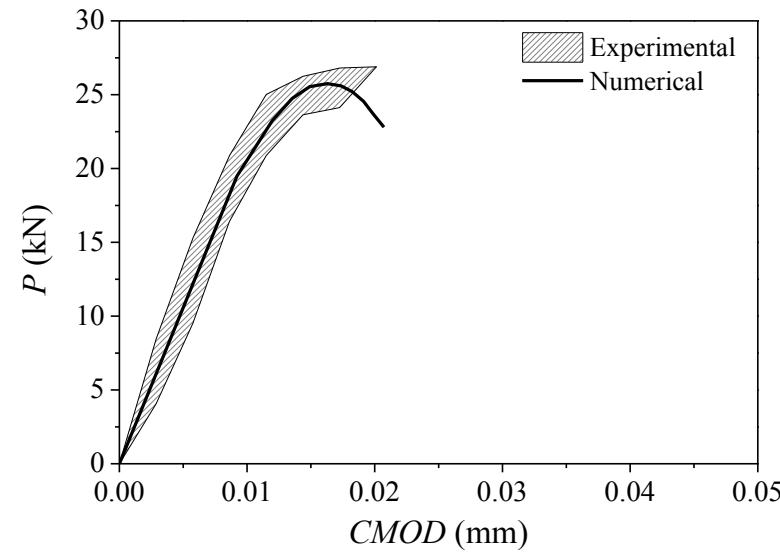

(d) Specimen C-R-235-5×5

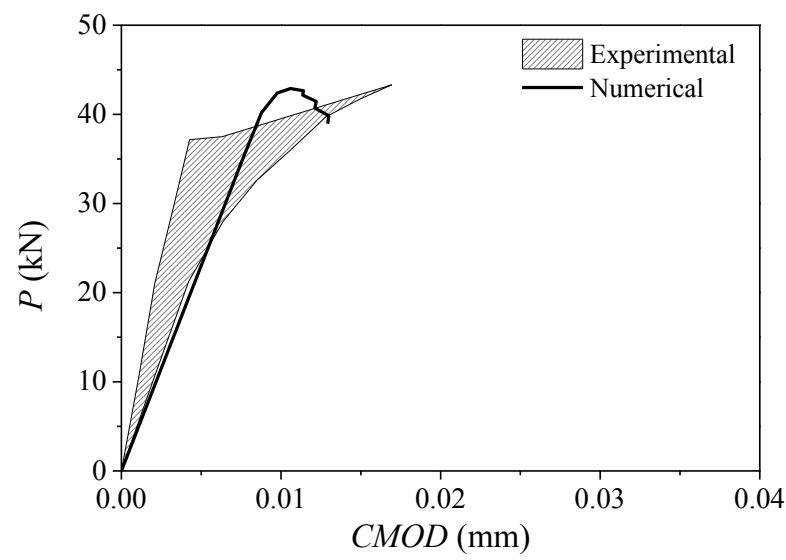

(e) Specimen C-R-250-7×7

Fig. 12. Comparisons of $P-C M O D$ curves with the test data on TPB and $\mathrm{C}-\mathrm{R}$ series specimens 


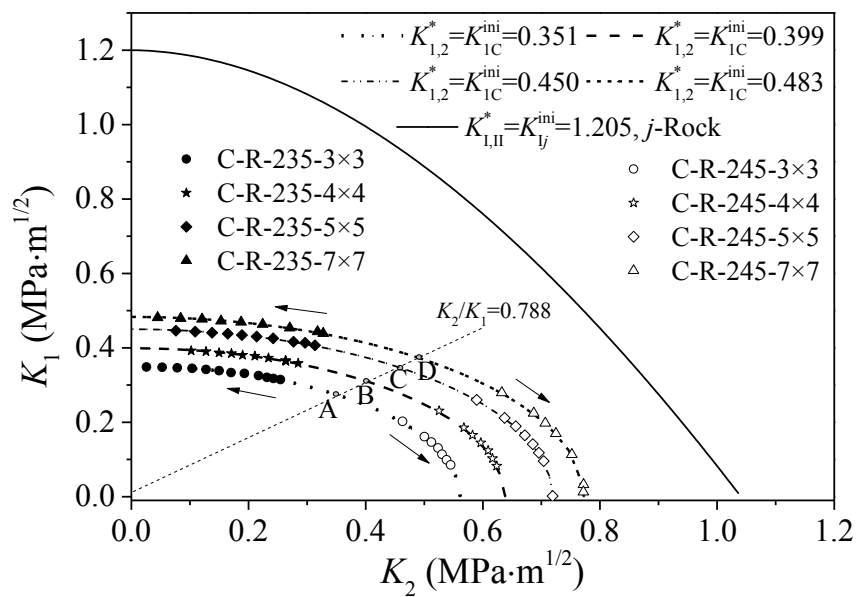

(a) Curves for the rock with $K_{\mathrm{I}, \mathrm{II}}^{*}=K_{\mathrm{Ij}}^{\mathrm{ini}}$ and $K_{1,2}^{*}=K_{\mathrm{lC}}^{\mathrm{ini}}$

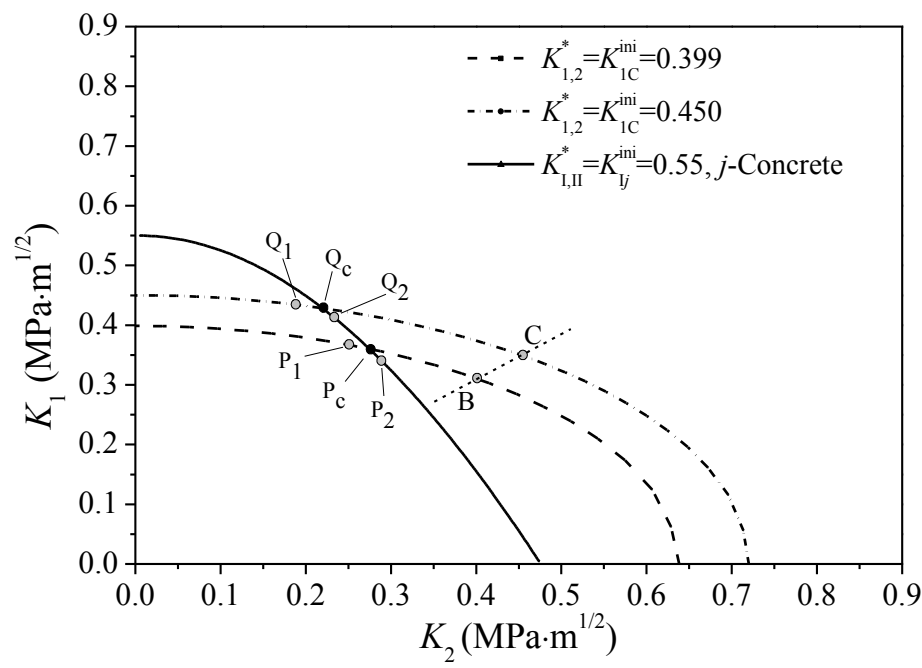

(b) Curves for the concrete with $K_{\mathrm{I}, \mathrm{II}}^{*}=K_{\mathrm{Ij}}^{\mathrm{ini}}$ and $K_{1,2}^{*}=K_{1 \mathrm{C}}^{\mathrm{ini}}$
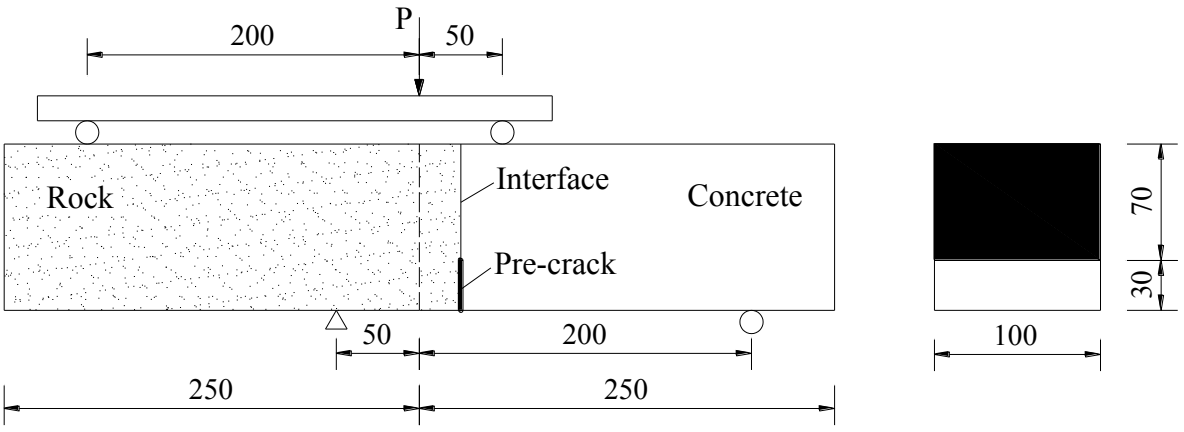

Fig. 14. Geometries of R-C series beams under four-point shear (FPS) 
655

656

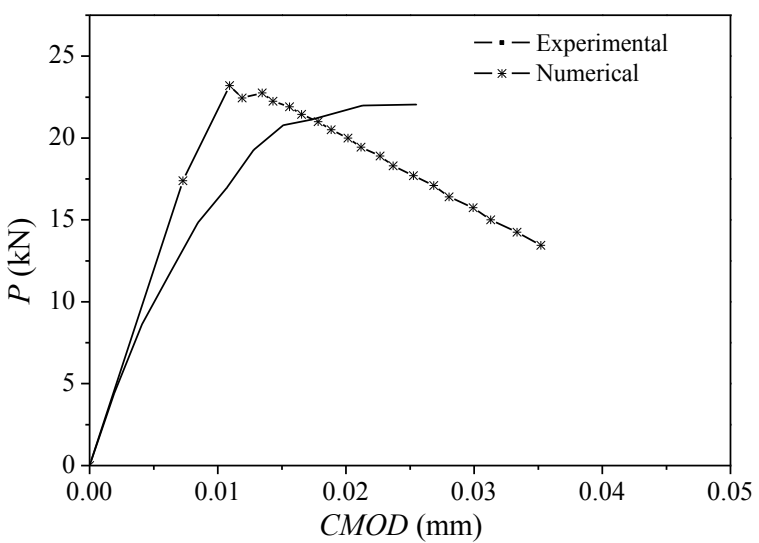

(a) P-CMOD curves

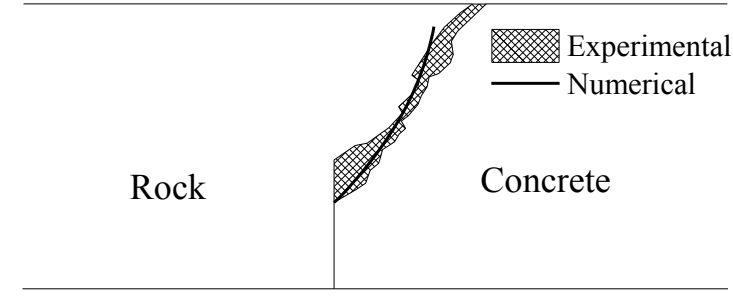

(b) Crack trajectories

Fig. 16. Comparisons of numerical $P-C M O D$ curve and crack trajectory with the test data 661

662 